\title{
El Diamante de Porter en los convenios bilaterales: Colombia
}

ELISA URBINA SÁNCHEZ*

\section{RESUMEN}

El éxito internacional de una industria, según el Diamante de Porter, está en función de la dotación de los factores de producción, de las condiciones de la demanda nacional, de las industrias conexas y del apoyo y rivalidad nacional. Al observar el mundo real diríamos que Colombia debería exportar los productos de aquellas industrias competitivas, por tener desarrollados los atributos de la teoría de Porter, e importar las mercancías donde los atributos no son favorables.

Los convenios bilaterales o multilaterales modifican las preferencias arancelarias y nos recuerdan que el beneficio arancelario es en ambos sentidos, tanto para exportaciones como importaciones. La producción nacional perderá la protección y

la competencia se manifestará en los precios; los productores nacionales deberán diferenciar la producción del resto de países del mundo con la aplicación de los fundamentos de la teoría de Porter.

En la relación económica bilateral y multilateral de Colombia, los productores deben desarrollar la creatividad comercial en función de la oferta nacional y la demanda mundial con estrategias que permitan singularizar los productos colombianos frente a los de América Latina a pesar de ser los mismos.

\section{PALABRAS CLAVE}

Exportaciones, Diamante de Porter y convenios bilaterales. 


\section{ABSTRACT}

The international success of an industry, according to Porter's Diamond, depends on the endowing of the production factors, on the National demand, on the related industries, on the national support and on the national rivarly. Observing the real world we could say that Colombia should export the competitive industries' products, because these have developed Porter's Theory's attributes, and import the merchandises that do not have advantageous atributes.

The bilateral or multilateral agreements modify the tariff's preferences and remind us that the tariff's benefit is in both sides: as for imports and for exports. The National production will lose the protection and the competence will manifest on the prices, the National producers then should make different their production from the other countries of the world's ones by an application of Porter's Theory.

On the Colombian bilateral and multilateral relationship, the producers should develop a creativity on trade based on the National offer and the global demand with strategies that should allow colombian products be singularized of the latin american ones, although they could be the same.

\section{KEY WORDS}

Exports, Porter's Diamond, bilateral agreements.

\section{LAS EXPORTACIONES EN EL CRECIMIENTO ECONÓMICO}

Hoy la riqueza de un país se mide por la producción y su crecimiento puede estar dado por las exportaciones. Las ventas al exterior de bienes o servicios pueden generar nuevos empleos, aumento en los ingresos, en el consumo y la inversión del país. Obtener utilidades derivadas del comercio exterior implica para los países exportadores poseer ventajas comparativas $y$, en especial, competitividad frente a los productores de los mismos bienes en el resto del mundo.

Las comparaciones internacionales son difíciles, al poseer cada país producción de bienes diferentes. Las teorías de comercio internacional a través del tiempo han argumentado las ventajas de las exportaciones y su participación en la generación de empleo y riqueza para los países.
La primera teoría surgió en Inglaterra en el siglo XVI, conocida como el Mercantilismo, y su principio fundamental estaba dado por los excedentes de oro y plata que conseguían a través de la balanza comercial positiva: exportaciones mayores a las importaciones ${ }^{1}$. Posteriormente, en 1776, Adam Smith, en su obra clásica The Wealth of Nations, atacó la suposición de los mercantilistas y habló de la ventaja absoluta: eficiencia en la producción de una mercancía ; los países deben especializarse en la producción de bienes que posean ventaja absoluta ${ }^{3}$.

Hoy, siglo XXI, decimos que Colombia tiene ventaja comparativa en el café y las flores frente a Japón. Situación que fácilmente podrían modificar los japoneses y que nos lleva a hablar de las ventajas comparativas de David Ricardo (1817): los países deben especializarse en aquellos bie-

\footnotetext{
HILL. CHARLES W. L. Negocios internacionales. McGraw Hill, Tercera edición, 2001, p. 138.

2 En la época de Adam Smith, los ingleses eran especialistas en la fabricación de textiles y los franceses en la producción de vino.

Op. Cit., p., 140.
} 
nes y servicios que puedan producir de manera más eficiente ${ }^{4}$. Teoría que complementaron Eli Heckscher (1919) y Bertil Ohlin (1933) al hablar de los recursos o factores de producción que posee cada país, ejemplo el café y el petróleo en Colombia. El hecho de poseer los recursos naturales para producir determinados bienes, ejemplo el café, no ha sido garantía para permanecer en el mercado e incrementar las ventas al exterior. Los ingresos de las empresas exportadoras dependen de la productividad y competitividad en los mercados internacionales.

\section{NUEVA TEORÍA DEL COMERCIO INTERNACIONAL}

La competencia en los mercados no es perfecta; tanto empresas como gobiernos pueden actuar estratégicamente afectando los flujos comerciales $y$, por tanto, el nivel de riqueza de una nación. En consecuencia, también pueden sufrir alteración las condiciones del mercado y la competitividad de las industrias.

En 1990, Michael Porter, de la escuela de negocios de Harvard, llevó a cabo una investigación para analizar el origen o causa de la competitividad de las naciones. Su objetivo final era desarrollar un marco conceptual que sirviera tanto para orientar a los empresarios y ejecutivos en la toma de decisiones, como para la formulación de políticas industriales orientadas a promover la competitividad de una nación.

Para enfocar su investigación, Porter postuló tres preguntas básicas ${ }^{5}$ :

1. ¿Por qué una nación llega a alcanzar el éxito internacional en una industria en particular?
2. ¿Qué influencia tiene una nación sobre la competitividad de sus diferentes industrias o segmentos industriales?

3. ¿Por qué las empresas de diferentes naciones eligen estrategias particulares?

Su teoría, respaldada con casos estudiados - 100 industrias y 10 naciones $^{6}{ }^{-}$, sugiere que los atributos de una nación moldean el entorno económico de tal forma que esto promueve o impide la creación de ventajas competitivas sostenibles en el largo plazo. El marco que utiliza Porter para explicar las ventajas competitivas comprende cuatro postulados que combinados conforman su teoría que denomina Diamante. Estos postulados son:

\section{1) Dotación de Factores}

El primer atributo del diamante lo constituye la condición de los factores. En este caso el concepto de la teoría económica clásica ha sido revolucionado completamente por Porter. Primeramente, el concepto neoclásico de la dotación o proporción de factores (mano de obra y capital) se concibe de un modo dinámico y no estático. Segundo, en lugar de la abundancia relativa, se considera a la escasez como fuente fundamental generadora de ventajas competitivas. El razonamiento es el siguiente: la abundancia normalmente genera una actitud complaciente, mientras que ciertas desventajas selectivas contribuyen al éxito de una industria por su impacto en la estrategia, dado que propicia la innovación.

Los factores de producción pueden separarse en generales versus especializados. Los factores generales son comunes a todas las industrias y

$4 \quad$ Ejemplo: Japoneses con la producción de semiconductores.

5 Citado por: Hill, Op. Cit., p 155. Y en: Gustavo-Adolfo Vargas. Michael Porter y la ventaja competitiva de las naciones. Instituto Mexicano de Ejecutivos de Finanzas, México, 1995.

6 Michael Porter, en su libro The competitive advantege of nations, publicó el estudio de las 100 industrias y 10 Países: Alemania, Corea, Dinamarca, Estados Unidos, Italia, Japón, Reino Unido, Singapur, Suecia y Suiza. 
por lo tanto no generan ventajas sostenibles, mientras que los factores especializados como infraestructura, educación y tecnología son específicos para cada industria. Dado el tiempo que lleva generarlos y su difícil acceso, estos factores contribuyen significativamente a la creación de ventajas competitivas sostenibles.

Porter argumenta que muy pocos factores se heredan. Por lo menos aquellos que generan ventajas competitivas sostenibles no son factores que se puedan heredar. Así pues, los gobiernos y las industrias deben fomentar la innovación mediante la creación de factores avanzados y especializados. Esto es de particular importancia cuando se pretende superar desventajas competitivas en un contexto de integración con economías más desarrolladas, como en el caso de Colombia.

\section{2) Condiciones de la demanda}

Otro atributo valioso es contar con demanda local sofisticada, ya que representa un poderoso incentivo para desarrollar una posición sólida internacionalmente. Esto estimula a las empresas a introducir nuevos productos al mercado con mayor rapidez. Los compradores locales pueden ayudar a las empresas a obtener ventajas si sus necesidades se asemejan a las tendencias de mercados globales.

La demanda nacional se compone de tres elementos significativos: i) naturaleza de las necesidades de los clientes locales (nivel de sofisticación); ii) tamaño y patrón de crecimiento del mercado interno, iii) mecanismos a través de los cuales las necesidades de los compradores locales están relacionadas con las empresas internacionales.

La importancia de la demanda no se define por su tamaño, sino por su composición y características. El desarrollo de los productos y la oportunidad con que se introduzcan al mercado de- penderán de las características de la demanda interna. Normalmente los mercados permiten que las empresas identifiquen rápidamente las necesidades de sus compradores, y éstos, a su vez, brindan retroalimentación oportuna sobre la calidad del producto. La cuestión del volumen y dimensión de la demanda puede suplirse con exportaciones.

\section{3) Empresas conexas e industrias de apoyo}

Este tercer atributo genera lo que Porter denomina clusters de empresas competitivas internacionalmente, que surgen por la relación entre diferentes industrias. Las empresas nacionales se benefician cuando sus proveedores son competidores globales. La presencia de empresas horizontalmente relacionadas e internacionalmente competitivas representa una fuente importante de ventajas competitivas; la relevancia de lo anterior es tanto mayor cuanto más interdependencia técnica exista entre las empresas integrantes de un cluster. Por ejemplo, el éxito internacional de una industria puede ejercer efectos multiplicadores sobre la demanda de un producto complementario, ya que a menudo las industrias relacionadas comparten actividades dentro de la cadena de valor o fabrican productos complementarios.

\section{4) La estrategia, estructura y rivalidad de las industrias}

El cuarto atributo general de la ventaja competitiva en el modelo de Porter es probablemente el más importante de los cuatro atributos, se relaciona con la intensidad de la rivalidad interna, la cual obliga a las industrias a competir en forma más agresiva, innovadora y a adoptar una actitud "global». La mayor rivalidad determina que las empresas tiendan a expandirse a otros mercados con mayor prontitud que en aquellos países donde estos patrones no existen. 
Hay un elemento adicional acerca de la rivalidad. La rivalidad interna es mucho más fuerte que la pura competencia económica tradicional. La rivalidad internacional es a menudo la excusa para el proteccionismo o la intervención gubernamental, mientras que con la rivalidad interna no existen excusas. Las reglas del juego son las mismas para todos.

Dos factores que hacen que la competencia se intensifique dentro de un país son la actitud de la gente y la estructura de capital. La conducta de la gente -motivación para trabajar y desarroIlar habilidades-, por ejemplo, puede influir la disposición o habilidad de la empresa para innovar y competir internacionalmente. $Y$ las metas de la empresa a menudo reflejan las características de los mercados de capitales nacionales y las prácticas de remuneración metas individuales versus metas de conjunto, industrias emergentes versus industrias maduras.

\section{EL DIAMANTE EN LAS EXPORTACIONES}

Los atributos del Diamante se refuerzan a sí mismos y constituyen un sistema dinámico. El éxito internacional de una industria está en función de la dotación de los factores de producción, de las condiciones de la demanda nacional, de las industrias conexas y del apoyo y rivalidad nacional. Al observar el mundo real diríamos que Colombia debería exportar los productos de aquellas industrias en las que los cuatro componentes del Diamante son favorables e importar las mercancías donde los atributos no son favorables.

El Diamante de Porter a nivel nacional se puede modificar con la intervención del gobierno y los fenómenos fortuitos. El grado de intervención juega un papel determinante en la competitividad de un país, por ejemplo, como catalizador de la innovación y el cambio, al cuestionar posiciones estáticas, forzar al sistema a mejorar constantemente e impulsar a las empresas a competir para acelerar el proceso de innovación.

La intervención del gobierno colombiano se observa en el Plan Estratégico Exportador, PEE, 19992009, que busca el fortalecimiento del sector productivo Colombiano y su orientación hacia el mercado internacional. Los objetivos estratégicos son:

1. Aumentar y diversificar la oferta exportable de bienes y servicios en función de la demanda mundial.

2. Incentivar e Incrementar la inversión extranjera para fomentar directa o indirectamente las exportaciones.

3. Aumentar la productividad empresarial y hacer competitiva la actividad exportadora.

4. Regionalizar la actividad exportadora ${ }^{7}$.

5. Desarrollar cultura exportadora ${ }^{8}$.

Al analizar el contenido de estos objetivos vemos que los principios estratégicos consideran los postulados de la teoría de Porter; por ejemplo en el tercero, el gobierno nacional dice: "Este objetivo busca mejorar continuamente la competitividad de nuestros productos mediante el incremento de la productividad de nuestra economía, el uso eficiente de los factores en el interior de las firmas, su localización en clusters regionales que les generen economías externas y la selección de estrategias adecuadas para producir bienes diferenciados de la mejor calidad $y$

7 La estructuración de los convenios de competitividad exportadora tendrán como fin el fortalecimiento de las ventajas competitivas regionales.

8 Todos los CARCE deberán tener una Mesa de Cultura Exportadora, la cual debe ser un espacio de encuentro interinstitucional para el intercambio de iniciativas, información y elaboración de propuestas en torno a la realidad de la formación e instrucción sobre negocios internacionales de la región. La Mesa debe determinar necesidades de capacitación y proponer y ejecutar programas y proyectos que desarrollen cultura exportadora. El pilar de la Mesa de Cultura Exportadora será el Consultorio de Negocios Internacionales y Comercio Exterior. 
en general la eliminación de obstáculos que generan sobrecostos en la producción y la exportación"”

Al comparar estos términos teóricos con la realidad de nuestras exportaciones, observamos que solo en la industria de flores se aplica la teoría, al incrementar su participación en el total exportado, al pasar de US \$280 millones en 1991 a US \$ 673 millones en el año 2002. El crecimiento de las exportaciones, $240 \%$, le ha permitido convertirse en el quinto producto de exportación colombiana, mientras que el valor de las exportaciones de café, petróleo y carbón viene en descenso en descenso, como observamos a continuación:

\begin{tabular}{|c|c|c|c|c|}
\hline \multicolumn{5}{|c|}{ EXPORTACIONES DE COLOMBIA } \\
\hline & & AÑoS & & \\
\hline & 2000 & 2001 & 2002 & Orden \\
\hline Miles de Dólares FOB & & & & 2002 \\
\hline TOTAL & $13,158,401$ & $12,301,490$ & $11,897,563$ & \\
\hline PRODUCTOS PRIMARIOS & $8,546,598$ & $7,088,094$ & $7,060,983$ & \\
\hline PRINCIPALES PRODUCTOS & $8,061,209$ & $6,527,613$ & $6,475,707$ & \\
\hline Café & $1,067,351$ & 764,167 & 772,202 & 3 \\
\hline Petróleo & $4,014,825$ & $2,590,536$ & $2,577,725$ & 1 \\
\hline Derivados del Petróleo (incluido Fuel Oil) & 760,663 & 694,521 & 697,283 & 4 \\
\hline Carbón & 892,882 & $1,178,765$ & 990,161 & 2 \\
\hline Ferroníquel & 211,404 & 235,230 & 272,464 & \\
\hline Banano & 433,678 & 364,875 & 401,584 & \\
\hline Flores & 583,610 & 610,319 & 672,555 & 5 \\
\hline Esmeraldas & 96,796 & 89,199 & 91,734 & \\
\hline OTROS AGROPECUARIOS & 334,809 & 387,452 & 302,678 & \\
\hline Camarones & 51,719 & 49,466 & 48,232 & \\
\hline Demás Agropecuarios & 245,359 & 267,568 & 193,138 & \\
\hline Franjas( pollos, carne de cerdo, leche, trigo,arroz, maíz, cebada, soya) & 37,730 & 70,418 & 61,309 & \\
\hline DEMÁS MINEROS & 150,581 & 173,029 & 282,598 & \\
\hline INDUSTRIALES & $4,610,747$ & $5,212,300$ & $4,834,921$ & \\
\hline AGROINDUSTRIALES & 676,572 & 729,623 & 736,739 & \\
\hline Azúcar & 194,258 & 216,990 & 210,686 & \\
\hline Productos del café & 108,922 & 94,805 & 92,554 & \\
\hline Demás agroindustriales & 268,247 & 326,414 & 363,170 & \\
\hline Franjas(azucar, aceite de soya y palma, soya y maíz) & 105,145 & 91,414 & 70,329 & \\
\hline INDUSTRIA LIVIANA & $1,656,995$ & $1,857,618$ & $1,768,281$ & \\
\hline Confecciones & 571,460 & 620,410 & 566,600 & 6 \\
\hline Textiles & 221,073 & 218,050 & 167,187 & \\
\hline Editoriales & 126,913 & 147,807 & 124,193 & \\
\hline Calzado & 32,965 & 40,344 & 27,053 & \\
\hline Manufacturas de cuero & 64,355 & 61,496 & 46,907 & \\
\hline Productos de plástico & 155,428 & 192,200 & 224,685 & \\
\hline Jabones, cosméticos, otros & 114,236 & 150,681 & 165,219 & \\
\hline Demás industria Liviana & 370,565 & 426,630 & 446,438 & \\
\hline INDUSTRIA BÁSICA & $1,612,860$ & $1,677,752$ & $1,562,255$ & \\
\hline Metalúrgica & 218,211 & 249,779 & 242,541 & \\
\hline Química básica & $1,203,563$ & $1,178,349$ & $1,074,796$ & \\
\hline Papel & 191,086 & 249,624 & 244,918 & \\
\hline MAQUINARIA Y EQUIPO & 431,367 & 503,951 & 420,137 & \\
\hline INDUSTRIA AUTOMOTRIZ & 232,954 & 443,356 & 347,509 & \\
\hline DEMÁS PRODUCTOS & 1,055 & 1,096 & 1,659 & \\
\hline
\end{tabular}

Fuente : Ministerio de Comercio Exterior, www.mincomex.gov.co

La productividad empresarial y la competitividad lograda en los productos colombianos durante el período comprendido entre 1991 y 2002, en parte, es el resultado del beneficio arancelario dado por Estados Unidos a través de la ley de Preferencias Comerciales Andinas, ATPA ${ }^{10}$, componente comercial

9 Op cit. www. Mincomex.gov.co

10 Andean Trade Preference Act. 
del programa de la Guerra contra las Drogas que el Presidente George Bush expidió el 4 de diciembre de 1991 y que se hizo efectiva en Colombia a partir de 1992. Estas preferencias arancelarias se prorrogaron el 6 de agosto de 2002 hasta el 2006 con el nombre de "Preferencias Arancelarias Andinas y de Erradicación de Drogas, ATPDEA".

El impacto del ATPDEA se evidencia en las exportaciones de flores, de petróleo, derivados del petróleo y confecciones, que representaron, en el total de valor exportado a Estados Unidos en el año 2002, el 11\%, el $44 \%$, el $10 \%$ y el $5 \%$ respectivamente. El valor exportado de petróleo de US\$2,253 millones en el 2002, frente al valor total de las exportaciones de Colombia del mismo, US \$2,577millones, representaron las destinadas a Norte América el $87 \%$, lo que mostró la dependencia económica; y si le agregamos el concepto de zonas económicas, vemos que las ventas totales a Estados Unidos sumaron US \$ 5.151 millones, representando el 43\% del total exportado por Colombia (US \$ 11.897 millones) en el 2002.

A continuación podemos ver el valor y productos de exportación a Estados Unidos:

\begin{tabular}{|c|c|c|c|c|c|}
\hline \multicolumn{6}{|c|}{ EXPORTACIONES A ESTADOS UNIDOS } \\
\hline & 1992 & Participación & 2002 & Participación & $\begin{array}{l}\text { Variación } \\
(\%)\end{array}$ \\
\hline Miles de Dólares FOB & & $\%$ & & $\%$ & 10 años \\
\hline TOTAL & $2,533,768$ & 100 & $5,151,171$ & 100 & 103 \\
\hline PRODUCTOS PRIMARIOS & $1,867,892$ & 74 & $4,292,293$ & 83 & 130 \\
\hline PRINCIPALES PRODUCTOS & $1,775,216$ & 70 & $4,032,679$ & 78 & 127 \\
\hline Café & 360,091 & 14 & 257,691 & 5 & -28 \\
\hline Petróleo & 794,450 & 31 & $2,253,050$ & 44 & 184 \\
\hline Derivados del Petróleo & 108,822 & 4 & 534,584 & 10 & 391 \\
\hline Carbón & 49,149 & 2 & 229,576 & 4 & 367 \\
\hline Ferroníquel & 15,182 & 1 & 16,000 & 0 & 5 \\
\hline Banano & 119,533 & 5 & 143,461 & 3 & 20 \\
\hline Flores & 257,911 & 10 & 544,781 & 11 & 111 \\
\hline Esmeraldas & 70,079 & 3 & 53,537 & 1 & -24 \\
\hline OTROS AGROPECUARIOS & 77,892 & 3 & 82,994 & 2 & 7 \\
\hline Camarones & 10,734 & 0 & 10,586 & 0 & -1 \\
\hline Demás Agropecuarios & 66,715 & 3 & 69,918 & 1 & 5 \\
\hline Franjas(pollo,cerdo,leche,trigo,cebada,maíz,arroz y soya) & 443 & 0 & 2,490 & 0 & 462 \\
\hline DEMÁS MINEROS & 14,785 & 1 & 176,620 & 3 & 1,095 \\
\hline INDUSTRIALES & 635,812 & 25 & 857,787 & 17 & 35 \\
\hline AGROINDUSTRIALES & 66,547 & 3 & 121,445 & 2 & 82 \\
\hline Azúcar & 19,061 & 1 & 15,091 & 0 & -21 \\
\hline Productos del café & 6,804 & 0 & 29,735 & 1 & 337 \\
\hline Demás agroindustriales & 38,578 & 2 & 68,282 & 1 & 77 \\
\hline $\begin{array}{l}\text { Franjas( aceite soya y de palma, azucar crudo, soya } \\
\text { agroindustrial). }\end{array}$ & 2,104 & 0 & 8,336 & 0 & 296 \\
\hline INDUSTRIA LIVIANA & 477,358 & 19 & 519,038 & 10 & 9 \\
\hline Confecciones & 261,836 & 10 & 280,770 & 5 & 7 \\
\hline Textiles & 48,325 & 2 & 16,623 & 0 & -66 \\
\hline Editoriales & 36,207 & 1 & 9,724 & 0 & -73 \\
\hline Calzado & 33,634 & 1 & 2,903 & 0 & -91 \\
\hline Manufacturas de cuero & 57,003 & 2 & 25,856 & 1 & -55 \\
\hline Productos de plástico & Futernt & e: whw. A & inctzrnes & gov.co $y$ & cálculos ${ }^{829}$ \\
\hline Jabones, cosméticos, otros & 5,429 & 0 & 4,030 & 0 & \\
\hline Demás industria liviana & 30,350 & 1 & 136,646 & 3 & 350 \\
\hline INDUSTRIA BÁSICA & 32,704 & 1 & 150,705 & 3 & 361 \\
\hline Metalúrgica & 8,829 & 0 & 48,811 & 1 & 453 \\
\hline Química básica & 20,400 & 1 & 92,842 & 2 & 355 \\
\hline Papel & 3,475 & 0 & 9,053 & 0 & 161 \\
\hline MAQUINARIA Y EQUIPO & 56,446 & 2 & 64,299 & 1 & 14 \\
\hline INDUSTRIA AUTOMOTRIZ & 2,757 & 0 & 2,300 & 0 & -17 \\
\hline
\end{tabular}


Los convenios bilaterales o multilaterales modifican las preferencias arancelarias y nos recuerdan que el beneficio arancelario es ambos sentidos, tanto para exportaciones como importaciones. La producción nacional perderá la protección y la competencia se manifiesta en los precios, los productores nacionales deberán diferenciar la producción del resto de países del mundo (aplicación de los fundamentos de la teoría de Porter).

La política comercial colombiana de incrementar las exportaciones de acuerdo a la demanda mundial continua; y en el actual plan de desarrollo, Hacia un Estado Comunitario, 2002-2006"1 , la intervención del gobierno se refleja en las negociaciones que está Ilevando con Estados unidos y Centro América en acuerdos bilaterales y multilaterales con todos los países del continente americano, Acuerdo de Libre Comercio para las América (ALCA). Con estos convenios busca equilibrar el comercio y eliminar barreras innecesarias en la apertura de los mercados.

\section{ACUERDO EQUILIBRADO}

La relación económica bilateral y multilateral de Colombia debe desarrollar la inteligencia comercial en función de la oferta nacional y la demanda mundial con estrategias que permitan singularizar los productos colombianos frente a los de América Latina a pesar de ser los mismos.

¿La productividad permitirá, cuando los aranceles Ileguen a cero, defender los ingresos de los colombianos frente al proteccionismo? La respuesta a este interrogante es compleja, la Organización Mundial del Comercio, en su declaración del año 2001en Doha ${ }^{12}$, se comprometió, a través de los representantes de los 128 países que la conforman, desarrollados y de menor cre- cimiento económico, a cumplir los 52 artículos de normas y programas de trabajo para rechazar el proteccionismo. Algunos de ellos son:

1. Mantener el proceso de reforma y liberación de las políticas comerciales, para garantizar así que el sistema cumpla plenamente la parte que le corresponde en la tarea de favorecer la recuperación, el crecimiento y el desarrollo.

2. El comercio internacional puede desempeñar una función de importancia en la promoción del desarrollo económico y el alivio de la pobreza. A ese respecto, serán factores importantes el acceso mejorado a los mercados, las normas equilibradas y los programas de asistencia técnica y de creación de capacidad con objetivos bien definidos y financiación sostenible.

3. Reconoce vulnerabilidad de los países menos adelantados y las dificultades estructurales especiales con que tropiezan en la economía mundial.

4. Reconoce a la OMC como único foro para la elaboración de normas comerciales y la liberalización del comercio a escala mundial, reconociendo asimismo que los acuerdos comerciales regionales pueden desempeñar un papel importante en la promoción de la liberalización y expansión del comercio y en el fomento del desarrollo.

5. Reafirma decididamente compromiso con el objetivo del desarrollo sostenible, enunciado en el preámbulo del Acuerdo de Marrakech (Medio ambiente y cooperación con el PNUMA).

11 Gobierno colombiano, Cartilla Bases del plan de desarrollo 2002 - 2006, HACIA UN ESTADO COMUNITARIO. Colombia, 2002, www.dnp.gov.co.

12 ORGANIZACIÓN MUNDIAL DEL COMERCIO, www.wto.org. 
6. Reafirma el derecho que asiste a los Miembros en virtud del Acuerdo General sobre el Comercio de Servicios de reglamentar el suministro de servicios y establecer nuevas reglamentaciones al respecto.

7. Reconoce los desafíos que plantea el número cada vez mayor de Miembros de la OMC, confirma su responsabilidad colectiva de velar por la transparencia interna y por la participación efectiva de todos los miembros, al tiempo que subraya el carácter intergubernamental de la Organización, y su compromiso de hacer más transparentes las actividades de la OMC, incluso mediante la difusión más eficaz y rápida de la información, y a mejorar el diálogo con el público.

8. La agricultura debe tener sistema de comercio equitativo y orientado al mercado mediante un programa de reforma fundamental que abarque normas reforzadas y compromisos específicos sobre la ayuda y la protección para corregir y prevenir las restricciones y distorsiones en los mercados agropecuarios mundiales.

9. Se convino celebrar negociaciones que tendrán por finalidad, según modalidades que se acordarán, reducir o, según proceda, eliminar los aranceles, incluida la reducción o eliminación de las crestas arancelarias, los aranceles elevados y la progresividad arancelaria, así como los obstáculos no arancelarios, en particular respecto de los productos cuya exportación interesa a los países en desarrollo.

10. Recalca la importancia del Acuerdo relativo a los Aspectos de los Derechos de Propiedad Intelectual relacionados con el Comercio (Acuerdo sobre los ADPIC). Este acuerdo debe aplicarse de manera que apoye la salud pública, promoviendo tanto el acceso a los medicamentos existentes como la in- vestigación y desarrollo de nuevos medicamentos.

11. Las razones en favor de un marco multilateral destinado a asegurar condiciones transparentes, estables y previsibles para las inversiones transfronterizas a largo plazo, en particular las inversiones extranjeras directas, que contribuirá a la expansión del comercio, y la necesidad de potenciar la asistencia técnica y la creación de capacidad en esta esfera.

12. Reconoce las necesidades de los países en desarrollo y menos adelantados de potenciar el apoyo a la asistencia técnica y la creación de capacidad en esta esfera, incluidos el análisis y la formulación de políticas para que puedan evaluar mejor las consecuencias de una cooperación multilateral más estrecha para sus políticas y objetivos de desarrollo, y el desarrollo institucional y humano.

13. Los miembros convinieron en que se lleve a cabo, en un grupo de trabajo bajo los auspicios del Consejo General, un examen de la relación entre comercio, deuda y finanzas, y de posibles recomendaciones sobre las medidas que cabría adoptar en el marco del mandato y la competencia de la OMC con el fin de mejorar la capacidad del sistema multilateral de comercio para contribuir a una solución duradera del problema del endeudamiento externo de los países en desarrollo y menos adelantados y de reforzar la coherencia de las políticas comerciales y financieras internacionales, con miras a salvaguardar el sistema multilateral de comercio frente a los efectos de la inestabilidad financiera y monetaria.

14. Convinieron, también, en que se lleve a cabo, en un grupo de trabajo bajo los auspicios del Consejo General, un examen de la 
relación existente entre el comercio y la transferencia de tecnología, y de posibles recomendaciones sobre las medidas que cabría adoptar en el marco del mandato de la OMC para incrementar las corrientes de tecnología hacia los países en desarrollo.

15. Reafirmaron que las disposiciones sobre trato especial y diferenciado son parte integrante de los Acuerdos de la OMC.

Globalmente, los resultados de estas negociaciones brindarán a largo plazo beneficios y constituyen un avance para los países exportadores. Situación poco favorable para Colombia, los principales productos de exportación tan solo son: petróleo, café, derivados del petróleo, flores, esmeraldas, banano, y ferroniquel. El crecimiento de la economía de nuestro país depende de la demanda interna del sector privado y el público. Las exportaciones representaron en el PIB de 1991 el $11 \%$ y asciende en el 2000 a 13\% hasta llegar al $17 \%$ en el 2001 y en el 2002 desciende a $16 \%^{13}$.

La dependencia del crecimiento económico de Colombia de la demanda interna en los próximos años puede llevar a la crisis, a la reducción del PIB, como consecuencia de la eliminación de la protección a la industria nacional. Al establecerse cero de arancel a los productos importados automáticamente los precios bajan y los colombianos se empobrecen y aportan sus ingresos al crecimiento de otros países, ejemplo Estados Unidos, Chile o Brasil.

Las exportaciones colombianas deben diversificarse, tratando de singularizar nuestros productos frente al resto de América Latina con estrategias de comercialización y de competitividad. Romper la tradición en los productos que hoy se exportan.

A continuación podemos ver el crecimientote de las exportaciones de los principales productos colombianos desde 1990 hasta el año 2002:

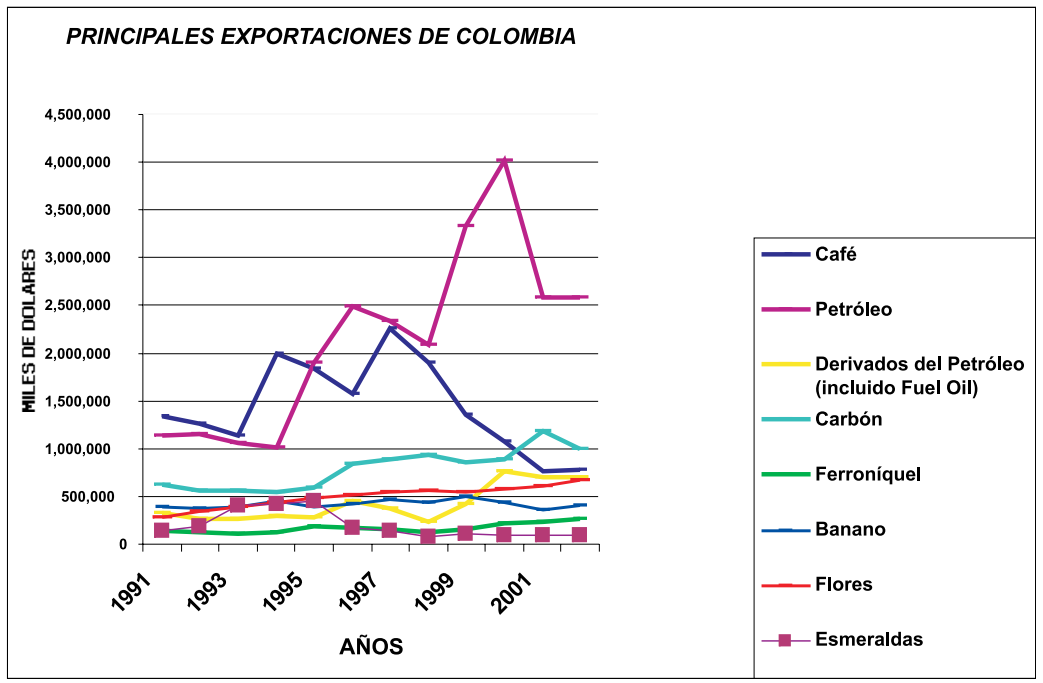

13 Fuente: cálculos del autor con información del DANE, www.dane.gov.co 


\section{FUTUROS CONVENIOS: BILATERALES O MULTILATERALES}

Los esquemas de convenios de Colombia datan de 1960, con la ALALC, Asociación de Libre Comercio de América Latina, grupo de integración que se transformó en 1980 en convenios bilaterales entre los 20 países que conforman el mercado común. El éxito de este tratado ha sido el Convenio de Pagos y Créditos Recíprocos que permite a los bancos centrales contabilizar los pagos de las importaciones y de las exportaciones, al finalizar cada trimestre, si la balanza es negativa, giran los dólares al país respectivo. Este mecanismo, el pasado año permitió el pago de los venezolanos a los exportadores colombianos.

En 1966 surge el Acuerdo de Cartagena, hoy se denomina Comunidad Andina de Naciones, CAN, son 37 años de negociaciones sobre aranceles, normas de origen y de valoración. El comercio multilateral entre Bolivia, Colombia, Ecuador y Venezuela muestra una balanza positiva para Colombia de US \$ 1.529 millones en el 2001 y de US \$ 1018 millones en el 2002.

Respecto a la balanza comercial de Colombia frente al resto de países, se observa solo positiva, pero en descenso, con Estados Unidos al pasar de US \$ 1.569 millones en el año de 1999 a US $\$ 573$ millones en el 2002. Situación similar se presentó con los países Centroamericanos, al ascender la balanza comercial de US \$ $147 \mathrm{mi}-$ llones en 1999 a US \$ 209 millones en el 2002.

El Acuerdo de Complementación Económica suscrito entre Chile y Colombia el 6 de diciembre de 1993 comprende normas de origen salvaguardia, programa de desgravación arancelaria de 5000 subpartidas (ejemplo: manzanas, papel, cajas de cambio mecánicas, vino, cátodos de cobre, vehículos, peras, uvas, tomates, tableros de madera, vidrios, neumáticos, productos a base de cereales, jugos, petróleo, etc), tratamien- to de materia de tributos internos, compras gubernamentales, inversión, coordinación de políticas comerciales y transporte. En este convenio la ventaja es para Chile, el déficit en la balanza colombiana está en ascenso, al pasar de - US \$ 31 millones en 1999 a -US \$68 millones en el año 2002.

Otra negociación internacional en la que participa Colombia es la referente a conformar Zona de libre Comercio entre la Comunidad Andina y el MERCOSUR. Estas conversaciones vienen desde 1998 con la firma del Acuerdo. La liberación del comercio se dará con las preferencias arancelarias y eliminación de restricciones no arancelarias (cuotas, licencias, contingentes). La balanza comercial con los países integrantes del MERCOSUR es deficitaria, por ejemplo con Brasil se incrementa el $144 \%$, al pasar de -US\$151 millones en 1999 a - US\$369 millones en el 2002.

Respecto a la Unión Europea, existe el Sistema Generalizado de Preferencias que la Comunidad Europea otorgó en 1990 para entrada libre de gravámenes y sin limitaciones de cuantía, durante un período de 4 años, a una serie de productos de exportación provenientes de Colombia, Ecuador, Perú y Bolivia. En 1994 la Unión Europea aceptó prorrogar estas concesiones por un período de diez años.

En relación al Grupo de los Tres, G3, está la negociación de un tratado de libre comercio entre Colombia, Venezuela y México. El acuerdo G-3, ACE N 33 fue suscrito en junio de 1994 en el marco de la ALADI en Cartagena. Este es un tratado muy amplio de libre comercio que en forma lineal anual, durante 10 años, libera arancelariamente el comercio de bienes entre los tres países participantes, partiendo del arancel vigente al 31 de diciembre de 1993. Se incluyeron en el acuerdo las preferencias arancelarias alcanzadas en el ámbito de la ALADI al igual 
que algunos temas que tienen que ver en forma directa o indirecta con el comercio de bienes, como cláusula de salvaguardia, prácticas comerciales y solución de controversias ${ }^{14}$.

La evaluación de las ventajas de los acuerdos internacionales es compleja. La balanza de Colombia con los países que ha firmado convenios nos muestran resultados desfavorables, excepto donde la ventaja es cero de arancel para las exportaciones colombianas. En la actualidad, las conversaciones del convenio bilateral con Estados Unidos y el multilateral con todos los países de América, ALCA, representan preferencias arancelarias en doble vía, es decir, Colombia no podrá gravar las importaciones de trigo y Estados Unidos igualmente aplicará el beneficio a las flores colombianas que lleguen a su país.

La competitividad de las exportaciones solo podrá diferenciarse cuando se apliquen los postulados de la teoría de Porter, a saber: dotación de factores de producción, condiciones de la demanda, empresas conexas e industrias de apoyo, y estrategia, estructura y rivalidad de las industrias.

A continuación podemos observar la dinámica de la Balanza colombiana:

\begin{tabular}{|c|c|c|c|c|}
\hline \multicolumn{5}{|c|}{ BALANZA COLOMBIANA POR PAÍSES GENERAL } \\
\hline \multirow[t]{2}{*}{ Miles de Dólares fOB } & \multicolumn{4}{|c|}{ Años } \\
\hline & 1999 & 2000 & 2001 & 2002 \\
\hline TOTAL & $1,625,992$ & $2,160,486$ & 304,149 & 6,448 \\
\hline COMUNIDAD ANDINA & 453,188 & 833,239 & $1,529,195$ & $1,018,007$ \\
\hline Venezuela & 130,510 & 424,792 & 996,462 & 389,910 \\
\hline Ecuador & 82,060 & 173,817 & 397,886 & 470,855 \\
\hline Perú & 248,330 & 236,967 & 126,517 & 151,941 \\
\hline Bolivia & $(7,712)$ & $(2,337)$ & 8,329 & 5,300 \\
\hline MERCOSUR & $310,006)$ & $249,402)$ & $482,414)$ & $561,003)$ \\
\hline Brasil & $151,540)$ & $102,626)$ & $311,507)$ & $369,180)$ \\
\hline Argentina & $40,437)$ & $40,548)$ & $(79,398)$ & $89,858)$ \\
\hline Uruguay & $120,668)$ & $108,766)$ & $95,408)$ & $100,854)$ \\
\hline Paraguay & 2,639 & 2,538 & 3,900 & $(1,111)$ \\
\hline CHILE & $31,114)$ & $(25,371)$ & $61,588)$ & $68,828)$ \\
\hline TLC & $1,362,734$ & $1,926,079$ & 141,625 & 365,764 \\
\hline México & $176,405)$ & $(196,969)$ & $(206,173)$ & $(166,177)$ \\
\hline EEUU + Puerto Rico & $1,569,433$ & $2,141,600$ & 387,962 & 573,847 \\
\hline Canadá & $(30,294)$ & $(18,551)$ & $(40,164)$ & $(41,906)$ \\
\hline CARIBE Y CENTROAMERICA & 147,112 & 219,179 & 292,823 & 209,641 \\
\hline MCC (Mercado Común Centroamericano) & 222,654 & 230,887 & 260,073 & 270,919 \\
\hline Panamá y Zona Franca & $(202,552)$ & $286,742)$ & $(188,337)$ & $(217,419)$ \\
\hline Caricom (Comunidad del Caribe) & 127,010 & 275,034 & 221,088 & 156,141 \\
\hline DEMÁS AMERICA & 127,601 & 30,843 & 11,505 & 109,747 \\
\hline UNIÓN EUROPEA & 199,512 & 64,501 & $270,730)$ & $(70,537)$ \\
\hline DMS EUROPA OCCIDENTAL & $164,704)$ & $(165,997)$ & $(185,842)$ & $(85,362)$ \\
\hline Ex-CAME (Concejo de Ayuda Mutua Económica) & 64,838 & 67,880 & 53,611 & 5,039 \\
\hline JAPÓN & $(123,532)$ & $(219,654)$ & $(281,969)$ & $(306,374)$ \\
\hline NICs (Nuevos Paises Industrializados) & $(175,101)$ & $(240,865)$ & $(306,300)$ & $(351,554)$ \\
\hline DEMÁS ASIA & $(71,441)$ & $(104,734)$ & $(168,972)$ & $(219,157)$ \\
\hline OTROS & 50,402 & 11,539 & 34,487 & 34,106 \\
\hline África & 8,181 & 9,906 & 3,476 & $(4,806)$ \\
\hline Medio Oriente & 36,605 & $(1,520)$ & 35,471 & 39,476 \\
\hline Oceanía & 5,617 & 3,153 & $(4,459)$ & (563) \\
\hline
\end{tabular}

14 El Congreso de la República de Colombia aprobó el Acuerdo del TLC-G3 mediante la Ley 172 de diciembre de 1994 . El decreto 1266 de mayo de 1997 promulgo definitivamente la vigencia del Acuerdo en Colombia con lo que se culminan los trámites internos necesarios para la plena puesta en vigor del tratado G3. Mediante el decreto 1197 del 26 de junio de 1998 se puso en vigencia la cuarta etapa del programa de desgravación en Colombia. 
La aplicación de los fundamentos de Porter en las industrias les ha permitido ingresar en el campo internacional, con el concepto de extensión del Mercado Nacional o ampliación de las perspectivas como parte del Mercado Multinacional o del Mercado Global.

Las exportaciones colombianas se realizan con diferentes grados de integración de la empresa con el resto del mundo. Algunas formas son: representaciones, empresas comercializadoras (trading companies), consorcios (grupo de exportadores), licencias (derechos de patentes, derechos de marcas registradas y derechos para utilizar procesos tecnológicos), franquicias y maquiladoras (manufacturas nacionales dentro del país extranjero).

Otra forma de integrarse al mercado internacional es con la creación de empresas, punto fundamental de las negociaciones en los convenios bilaterales al hablar de inversión en la comercialización de productos entre los dos países. Hoy las Empresas Conjuntas (joint-ventures) ${ }^{15}$ deciden compartir la dirección con una o más empresas extranjeras y formar una tercera empresa, especialmente, por la reducción de los riesgos políticos y económicos. A las empresas internacionales les interesa una empresa conjunta para desarrollar el mercado extranjero, utilizando los conocimientos y sistema de distribución de la empresa local. Además de proporcionar una base de exportación para una región cuando el socio está en un país que pertenece a un mercado común o grupo de integración económica. Ejemplos: Bimbo de Colombia S.A (Noel y Bimbo México) y Dulces de Colombia S.A. (Noel y Chupa Chips de España).

En las negociaciones bilaterales otro punto de análisis son las empresas Multinacionales ${ }^{16}$ y las Globales; en el primer caso, los accionistas están principalmente en el país de origen, el territorio nacional es todavía el mercado principal y las subsidiarias extranjeras operan como accesorios de las oficinas centrales. En el segundo caso, la integración y la creciente intercomunicación de los mercados han transformado las estructuras administrativas de las organizaciones. Hoy las empresas transnacionales ya no son de ningún país y pertenecen al que brinda la mayor tasa de retorno y de garantías; con ello el poder económico se ha multiplicado.

La competencia global tiene un renovado interés en algunos principios empresariales. Reduce los marcos temporales y se centra en la importancia de la calidad, de los precios competitivos $y$ de los productos innovadores. El tiempo se convierte en un bien preciado para las empresas y la tecnología en expansión acorta los ciclos de vida de los productos y crea mayores oportunidades para los productos nuevos, que posiblemente, no estarán en el ámbito de las negociaciones bilaterales.

15 PHILIP CATEORA. Marketing International, México, McGrawHill, 1995, pp. 357 y 358.

16 PAUL KRUGMAN, MAURICE OBSTFELD. Economía Internacional, España, McGrawHill. 1996, pp. 199 a 201. 


\section{BIBLIOGRAFÍA}

CHARLES W. L. HILL Negocios internacionales McGraw Hill, Tercera edición, 2001.

PHILIP CATEORA, Marketing International. México: McGrawHill, 1995.

PAUL KRUGMAN MAURICE OBSTFELD. Economía Internacional. McGrawHill, España, 1996.

GUSTAVO-ADOLFO VARGAS. Michael Porter y la ventaja competitiva de las naciones, México: Instituto Mexicano de Ejecutivos de Finanzas 1995.

MINISTERIO DE COMERCIO EXTERIOR, Plan Estratégico Exportador, PEE, 1999-2009, www.mincomex.gov.co.

GOBIERNO COLOMBIANO, Cartilla Bases del plan de desarrollo 2002- 2006, HACIA UN ESTADO COMUNITARIO. Colombia, 2002, ww.dnp.gov.co.

ORGANIZACIÓN MUNDIAL DEL COMERCIO. Declaración de Doha, 2001, www.wto.org. 